\title{
LEONESISMOS Y OCCIDENTALISMOS EN LAS LENGUAS Y DIALECTOS DE ESPAÑA
}

Manuel Ariza

El título muestra ya de entrada uno de los problemas esenciales que tenemos al estudiar el léxico de otras zonas no leonesas, como pueden ser la extremeña, la andaluza o la canaria. No es nada nuevo. Lo mismo ocurre, por ejemplo, en la otra zona peninsular con los aragonesismos, catalanismos y occitanismos, como tantas veces ha puesto de relieve Germán Colom.

Es verdad que la fonética nos puede a veces ayudar en la determinación geográfica de un término, como - por ejemplo - la ausencia de diptongación de una $\mathrm{E}$ o una O tónicas latinas en principio puede significar un origen gallego-portugués, y, al contrario, la diptongación con yod nos puede hablar de su origen leonés - pongo por caso -; pero no siempre es así: una palabra con F- inicial mantenida tanto puede ser gallego-portuguesa como leonesa, e incluso castellana.

Sin el apoyo de la fonética es difícil distinguir en ocasiones los auténticos leonesismos cuando la misma palabra se ha conservado - o se daba en el pasado - tanto en el gallegoportugués como en el leonés. Por ello muchas veces hemos de hablar simplemente de occidentalismos, sin poder estar seguros de si la voz ha sido propagada por leoneses o por portugueses.

Parece lógico pensar que los leonesismos y occidentalismos deben aparecer con más frecuencia en el extremeño, con menos intensidad en el andaluz y todavía con menos índice de frecuencia en el castellano. Así ocurre, efectivamente, por razones tanto históricas como geográficas.

Empecemos por estos últimos. Los leonesismos del castellano son - según Corominas los siguientes: ambos, brizo, caraba, cócora, colloño, columpiar, comba, congrio, cuelmo, desbullar, desmirriado, engarnio, feo, fisgar, gorullo, lacio, lancha I, orvallo, perpiaño, piara, pulpo, quejumbre, rallbar, redaya, regaifa, sarpullido, sobrero, teso, tojino, torreón, urna y volver ${ }^{1}$. No son muchos: 32. Ya de entrada sorprende que no aparezca fabada - que, por cierto, no está en el Diccionario de Autoridades -, pero debe tratarse de un despiste. Y no se diga que no es un leonesismo sino un asturianismo porque de lo que estamos hablando es del dialecto del antiguo reino de León.

\footnotetext{
1 Algunos fueron examinados por Alvaro Galmés en su artículo "Dialectalismos" (ELH, II, Madrid, 1959, 1os leonesismos en pp. 310-313), sin añadir nada nuevo a lo dicho por Corominas
} 
Bien, examinando la lista antes citada, estoy seguro de que hay una serie de palabras cuyo significado es desconocido quizá para una mayoría de hispanohablantes, como pueden ser: brizo: "cuna para mecer al niño", cócora: "persona molesta e impertinente en demasiado", coloño: en Burgos "cesto", en Santander "haz de leña"; cuelmo "colmo", desbullar: "quitar la cáscara o envoltura de algunas cosas", engarnio: "plepa, persona o cosa que no vale para nada", gorullo: "pella de lana, masa, engrudo, etc", perpiaño: "piedra que atraviesa toda la pared", ralbar: "dar la primera reja de arado a las tierras" (el Diccionario de la Academia dice que es voz leonesa), redaya: "red para pescar en los ríos", regaifa: "torta, ornazo. Piedra circular y con un canal en su contorno de los molinos de aceite", teso: "cima de un cerro. Sitio en que se efectúa la feria de ganados" (en Toledo), tojino: "pedazo de madera de los barcos, de distintas formas y utilidades".

Con estas definiciones de la Real Academia ya sabemos algo más, entre otras cosas además del significado - que ralbar no es un leonesismo del castellano sino un mero término leonés, que no es lo mismo. El diccionario académico cita relvar "levantar el barbecho" sin mencionar procedencia. No estoy seguro de que sea voz castellana ${ }^{2}$, pero sí leonesa ${ }^{3}$ y extremeña. Pero, en fin, el mismo Corominas dice que ralbar es voz leonesa. Sin embargo, el hecho de que Américo Castro registre relvar en el glosario de Toledo (s. $\mathrm{XV}$ ) puede indicar mozarabismo o, al menos, voz autóctona.

Con lo que acabamos de decir creemos que podemos centrar bien el problema, pero, por abundar más, examinemos el caso de brizo, que - como vimos - viene en el diccionario académico sin ninguna notación local. La voz se registra ya en el Diccionario de Autoridades, que cita a Covarrubias como única autoridad. Sin embargo Covarrubias habla en esta palabra en tercera persona del plural: "la cuna en que mecen al niño", lo que ya indica que no es castellana, y, efectivamente, más adelante dice "los mecen o columpian, en Portugal y algunas partes de Galizia". Como podemos comprobar, la aparición en el diccionario no se debe más que a una mala lectura de Covarrubias por parte de Autoridades ${ }^{4}$. Corominas dice que es voz leonesa que se da en Zamora y Salamanca, aunque también se encuentra en León ${ }^{5}$.

Pasemos a examinar los leonesismos de Corominas.

Ambos, según Corominas esta forma, frente a la castellana amos, se debe a dialectalismo leonés ( aunque con influjo latino) Es teoría que no se mantiene hoy pues generalmente se acepta que la evolución del grupo MB > M es meramente fonética y no fonológica, por ello

\footnotetext{
${ }^{2}$ No le recoge García de Diego en su Diccionario etimológico, ni F. González Ollé - El habla de la Bureba - ni A. Alcalá Venceslada.

3 En varias monografías, vid E. Miguélez: Diccionario de las hablas leonesas, León, 1993; así como J.C. González Ferrero: Sociolingüística y variación dialectal. Estudio del habla de Flores de Aliste, Zamora, 1986.

${ }^{4}$ Autoridades trae también brezo, sobre la que dice: "Es también lo mismo que Brizo. Vease. En algunas partes y provincias de España usan más de la palabra Brezo, que de brizo, aunque en la realidad se dice brizo y brizar". No sabemos a qué partes y provincias se refiere ¿las leonesas?.

${ }^{5}$ En Babia y Laciana briezu, bricio en Villadepera de Sayago, Bercianos del Real Camino, etc. Para la crítica de A. Llorente a la etimología de Meier, vid. RFE, XLVI, 1963, p. 207.
} 
tiene muchas excepciones, como ya dijo hace tiempo A. Badía. No merece la pena que me detenga más en ello.

Caraba, hoy se conserva en dialectos occidentales - salmantino, extremeño -; sin embargo no lo encuentro en las monografías leonesas ${ }^{6}$. Es arabismo de documentación tardía y es posible que el "rústico" de Autoridades o el "labradores" de Hernán Núñez pueda referirse a una determinada zona. En Salamanca "ir de caraba" significa "ir de juerga".

Cócora: También de documentación tardía (siglo XIX), registrada en zonas de Hispanoamérica. No deja de ser sintomático que la primera documentación sea de Bretón de los Herreros. Para Corominas el posible leonesismo vendría por la fonética: como presunto derivado de CLUECA, el paso de /1/ a /r/ indicaría leonesismo. Sin embargo, se trata de una palabra onomatopéyica sin más problemas.

Coloño: curiosamente nada dice Corominas de esta rara voz que indique leonesismo ${ }^{7}$, que, al parecer, se da también en Santander ${ }^{8}$ y Burgos $^{9}$. Corominas habla de que se emplea también en Portugal.

Columpiar: Ya García de Diego criticó el supuesto leonesismo defendido por Corominas, basado una vez más en razones fonéticas ${ }^{10}$. Lo más gracioso es que dice que "procede del leonés columbiar, y este del santand. y astur. columbarse, calumbarse". Pero la forma con B se da también en la Rioja y en zonas de América - Ecuador, Argentina - ¿leonesismos en América? Difícil me es admitirlo. Pero, en fin, limitándonos a Andalucía, con b aparece en puntos de Córdoba cerca de Ciudad Real y de Jaen, en la provincia de Jaen y en un punto de Málaga (Alea). Demasiado lejos para ser leonesismo.

Comba: De nuevo es el grupo MB el que le hace suponer origen leonés o mozárabe. No añadimos más a lo ya dicho en otras palabras.

Congrio: Leonesismo - según Corominas - por la i. Para explicar lo inexplicable dice Corominas nada menos que "J. Ruiz llama al congrio $<<$ Conde de Laredo $>>$, indicando que el comido en Castilla se pescaba especialmente en la Montaña, zona comprendida en parte dentro de los límites del dialecto leonés". Ahí es nada. La crítica del profesor Mondéjar me exime de más comentario ${ }^{11}$.

Cuelmo: no es un leonesismo, es voz leonesa y gallegoportuguesa.

Desbullar: Es un portuguesismo, que recoge la Academia en el siglo XIX, y no sé si realmente es palabra castellana. García de Diego no dice en dónde se emplea, dando el

\footnotetext{
${ }^{6}$ Guzmán Alvarez, Millán Urdiales, etc.

${ }^{7}$ Lo recoge E. Minguélez, ob. cit.

8 Vid M. Alvar: Estudios de geografía linguiística, Madrid, 1990, pp. 76 y 100

9 Según V. García de Diego: "Miscelánea filológica", RFE, XII, 1925, p. 15.

10 Como el castellano, en su opinión, no tiene MB, sustituye el grupo por MP!

11 Vid J. Mondéjar: "Congrio y zafío. Un capítulo de ictionimia mediterránea y atlántica", VRom, 41, 1982, pp. 206-219. Recogido en Dialectología andaluza, Granada, 1991.
} 
significado de "sacar la ostra de su concha"12. La encuentro en el habla de Ancares ${ }^{13}$, lo que no puede confirmar su carácter occidental.

Desmirriado: Es un ejemplo más de los razonamientos de Corominas: "como mirriado se emplea particularmente en Asturias, hay motivo de sobra para sospechar un origen leonés o gallegoportugués. Por lo demás, un ejemplo de mirrado 'consumido' se halla ya en el Canc. de Baena, en poesía de Iñigo de Mendoza, personaje castellano, aunque de prosapia navarra". Pero, por si fuera poco, el primer testimonio es de Bretón de los Herreros, y hoy se dice en toda Andalucía.

Engarnio. Es palabra dudosa cuyo presunto leonesismo no es más que una hipótesis de Corominas. En Salamanca hoy puede significar "prisa". Curiosamente E. Minguélez ${ }^{14}$ dice que la voz procede del castellano.

Feo: Para Corominas es leonesismo por la conservación de F-, sin embargo no vemos que sean leonesismos las demás palabras que han conservado F- en castellano. No diré más sino que no es ningún argumento válido.

Fisgar: Es mera hipótesis ya comentada.

Gorullo: La / $/ /$ proviene de una yod segunda, por lo que puede ser leonesismo o mozarabismo.

Lacio: De nuevo Corominas basa su hipótesis en la fonética, pues supone que la evolución FL- > L no es castellana, pero lo más curioso es que nadie ha sostenido que esta evolución sea leonesa, zona en la que se produce la palatalización extrema o, en todo caso, en el sur, se da el rotacismo de la líquida.

Lancha: También en esta palabra de etimología dudosa el leonesismo vendría de la evolución PL- > L- (de *plancula), que según Corominas - amparándose en la autoridad de Menéndez Pidal - es solución leonesa, pero no encuentro en ninguna parte que D. Ramón diga eso.

Orvallo: no es un leonesismo, sino voz leonesa y gallegoportuguesa, y, en general de la zona cantábrica

Perpiaño: De esta voz, de etimología dudosa, dice Corominas que puede ser leonesa o aragonesa por el diptongo en IA.

Piara: Aquí sí que tenemos problemas porque no se sabe la etimología, y el supuesto leonesismo se debe a la terminación -ARA, desarrollo femenino de la terminación leonesa en -ar tipo castañar, pumar. Ahí es nada.

Pulpo: también aquí la explicación es fonética, la O latina pasaría a U por metafonía asturiana, ya que - dice - "tratándose de un nombre de animal marino, es fácil que estemos

12 En la segunda parte de su diccionario - s.v. *defollare - no la cita como castellana. Lo que hay es el asturiano debuyar.

13 J.R. Fernández González: El habla de Ancares, Oviedo, 1981.

14 Ob. cit. 
ante una forma primitivamente leonesa". Menos mal que dice también que en español puede darse la evolución de $\mathrm{O}>\mathrm{U}$ como en dulce, pulpa y $\operatorname{surco}^{15}$.

Quejumbre: Dice que es voz leonesa o de influjo occidental sin dar los motivos

Redaya: Solo dice que parece leonesismo

Regaifa: Este arabismo, que significa "losa, torta", parece propio del leonés y del gallegoportugués.

Sarpullido :Palabra también de etimología discutida que parece más bien gallegoportuguesa que leonesa.

Sobrero: con el significado de "alcornoque" solo se da en la Ribera del Duero y es un lusismo

Teso: Una vez más es voz leonesa. El Diccionario Académico señala en Avila la acepción "cada una de las divisiones del rodeo en las ferias", y, como decíamos, en Toledo "sitio en donde se efectúa la feria de ganados". La acepción de "meseta en una colina" arranca de Autoridades que cita a Covarrubias; sin embargo este dice lo siguiente: "Un campo de Salamanca, de la otra parte del puente, donde se haze la feria famosa del vestiaje por Nuestra señora de setiembre". Frente a la abundante documentación occidental, la documentación de Toledo del Diccionario Académico es rara. Habría que mirar de dónde ha sacado la información.

Tojino: Al parecer derivado de TUFO, leonés por la terminación -ino. En opinión de Corominas "estamos ante una denominación nacida en la costa Cantábrica, con la pronunciación aspirada de la h que es propia de Santander y Oriente de Asturias". Luego es cántabro no leonés. De todas formas TUFO "mechón, penacho" - la supuesta etimología es palabra inexistente, de la que se supone origen germánico.

Torreón: Dice que quizá sea variante fonética leonesa de "torrejón"

Urna: Baste decir que es un cultismo de fines del siglo XVI

Volver: Pese a estar en el índice Corominas en las adiciones habla del leonés baltar. Es evidente que "volver" es palabra castellana.

Curiosamente Corominas no recoge entre los leonesismos la palabra nalga - aunque sí lo afirma en la correspondiente voz -, cuya forma fonética habla claramente de su origen leonés. Esta vez sí. Lo que no sabemos es por qué el leonesismo triunfó en castellano. ¿Eran famosas las nalgas leonesas en la Edad Media?

Recapitulemos sobre lo visto hasta ahora. Pero antes hemos de reflexionar sobre el concepto de leonesismo. Dice el DRAE que leonesismo el voz, giro, etc procedente del dialecto leonés, que es prácticamente la misma definición del Diccionario de Lázaro Carreter. Pero es incompleta o poco esclarecedora, porque no se pueden meter en el mismo saco las

\footnotetext{
15 Montgomery considera que la U se debe al influjo de la L implosiva. Vid T. Montgomery: "Vocales cerradas antietimológicas en español", ZRPh, XCIX, 1983, 1-4, pp. 355-366
} 
voces leonesas que perduran en el ámbito leonés, es decir: que no han sido sustituídas por las formas castellanas, y las palabras que han pasado al acervo común del español, caso de nalga. ¿Una palabra que se da únicamente en el español hablado del antiguo reino de León puede ser considerada realmente un leonesismo o, por el contrario, no es mejor pensar que se trata de un término leonés sin más? ¿Podemos decir que el vocabulario de los bables están llenos de leonesismos? Ya sé que se me puede argüir que en Salamanca, en casi toda la provincia de León y Zamora lo que se habla es castellano, y que por lo tanto los términos leoneses que han sobrevivido son ciertamente - y valga la redundancia - leonesismos. Y en un sentido amplio es verdad. También puedo decir que el andaluz está lleno de andalucismos, y de hecho al léxico peculiar de Madrid se le llama "madrileñismos", pero no es lo mismo insisto - la perduración de voces "patrimoniales" frente a las voces del castellano "normativo", que la propagación de una voz fuera de su ámbito originario o histórico.

Estas disquisiciones terminológicas - que a mí nada me gustan - son importantes para que nos podamos entender. Parece, pues, que debemos considerar leonesismos -stricto sensu - aquellas palabras de origen leonés que se han generalizado o difundido por ámbitos lingüísticos históricamente no leoneses. Desde esta perspectiva vamos a examinar lo estudiado hasta ahora.

Son palabras leonesas - no leonesismos - o en todo caso del occidente peninsular brizo, caraba, cuelmo, orvallo, rallbar, regaifa y teso. Parecen lusismos sarpullido y sobrero. Son palabras con problemas etimológicos coloño, engarnio, gorullo, perpiaño y redaya. No son en absoluto leonesismos esmirriado, quejumbre, tojino, torreón, urna y volver. El leonesismo se debe a supuestas leyes fonéticas de tipo neogramático, hoy desechadas, en ambos, cócora, columpiar, comba, congrio, feo, fisgar, lacio, lancha, piara y pullpo.

Lamento, por lo tanto decir que ninguno de los leonesismos de Corominas lo son, y sí, en cambio, malga, que no viene en el índice. De lo que me alegro; porque, quitando términos agrícolas y técnicos, los supuestos leonesismos tienen todos unos significados negativos: además de nalga, esmirriado feo, fisgar, lacio, cócora, engarnio. Pobres leoneses.

Si los leonesismos son escasos en el castellano, como era de esperar, no lo son en zonas de influjo leonés, como sucede con Extremadura y el occidente de Andalucía.

No me voy a detener en los leonesismos fonéticos o morfosintácticos del estremeño. Solo diré una vez más que el extremeño no pertenece al dominio leonés - salvo el ángulo norocciental -, como se sigue diciendo desde Menéndez Pidal, puesto que la aspiración extremeña es la meridional y no tiene nada que ver con la del asturiano oriental.

Permítaseme recordar que principalmente hay dos etapas en la reconquista de Extremadura: la primera, que ocupa el tiempo que discurre entre el siglo XII y primeros años del siglo XIII la frontera no rebasa el río Tajo, en esta época los reinos de León y de Castilla eran independientes, y por lo tanto las repoblaciones se hicieron con gentes de cada reino en sus zonas respectivas, cuya frontera era grosso modo la actual carretera nacional - la vía de la 
Plata -. La segunda etapa empieza en la década de los años veinte del siglo XIII con una rápida reconquista de prácticamente toda la tierra de Extremadura. Para esta época hay que señalar un hecho de capital importancia: en 1230 se unen definitivamente Castilla y León con Fernando III. Con ello la reconquista y, sobre todo, la repoblación se va a a hacer con gentes llegadas de todas las zonas cristianas. Pero además - y esto conviene recordarlo - en el siglo XIII empieza a producirse la "castellanización" del reino de León, o, dicho de mejor forma, comienzan los leoneses a considerar que el habla de Castilla es norma de mayor prestigio que la propia y van dejando sus peculiaridades.

Los hechos mencionados van a configurar - como no podía ser menos - el habla de Extremadura y, en lo que a nosotros toca, la extensión e intensión de los dialectalismos leoneses en Extremadura y también en Andalucía, como veremos más adelante.

Es por lo tanto evidente que los leonesismos de todo tipo son más intensos en el ángulo noroccidental de Cáceres, al norte del Tajo, que en el resto del territorio. Y es normal. Aunque los repobladores - una vez producida la unión política - puedan proceder de ambos reinos, es lógico que lleguen de las zonas más próximas, es decir del reino de León Salamanca y Zamora principalmente - y de la vecina Castilla - Avila y Toledo sobre todo.

Sin duda en lo antiguo hubo un más acusado dialectalismo leonés - tanto mayor cuando más al norte y al occidente -, que se fue perdiendo con el paso de los años, como ocurrió en otras zonas de España. Tampoco hemos de olvidar que desde el principio hubo una cierta emigración portuguesa, que explica que algunos lusismos tengan una amplia difusión por el occidente de España. Digo esto porque - como ya he señalado - en numerosas ocasiones podemos dudar si estamos ante un leonesismo o un lusismo, por lo que se hace preferible en estos casos hablar de occidentalismos sin más.

En la documentación medieval, lo normal es que los textos estén escritos en castellano, como norma de prestigio que ya era, y, solo de vez en cuando al escriba se le escapa algún rasgo dialectal. Ya a mediados del siglo XIII hay documentos con yeismo leonés - conceyo, fiyo; en los fueros y otros textos medievales aparece de vez en cuando el yeismo leonés, la lateralización de la dental implosiva - dulda, julgar, selmana, etc - y el rotacismo de los grupos con L - preito, prazo, comprir, etc.-. En cuanto al léxico es más difícil que se escapen dialectalismos; solo en las ordenanzas del concejo de Alcántara he encontrado algunos occidentalismos, como borda "borde", carballar "robledal", hozil "eslabón para encender fuego", pomares "manzanares", púcaro "búcaro", senara "serna" y tesón "tipo de red"16

En el extremeño actual hay bastantes palabras de procedencia occidental o simplemente leonesa, como achiperres (trastos), bandul (vientre), bogalla o abogalla (agalla del roble), cuadril (cadera), engurrirse (morirse de frío, ponerse algo flojo y arrugado), falar (hablar), farraguas (ser descuidado en el vestir), galapero (peral silvestre), palrar (charlar), pínfano (mosquito), senara (cosecha), etc.. Otras son occidentalismos, como

\footnotetext{
16 Vid mi artículo "Dos estudios de Historia Lingüística de Extremadura", Anuario de Estudios Filológicos de la Universidad de Extremadura, VIII, 1985, pp. 7-18
} 
carozo (hueso de la fruta), coruha (lechuza), millo (maíz), piche o espiche (botijo), etc.

Repasando la letra A del Diccionario extremeño de Antonio Viudas registro los siguientes leonesismos léxicos: abangar (torcerse una cosa, estar algo hueco), albilla (guisante), almargeña (zueco), argadillo (aguaderas) y asturar (tostar); y occidentalismos como abafar (pudrirse la carne), abalar (marcharse), afechar (cerrar), etc. A estos hay que añadir los que muestran su origen por rasgos fonéticos, como bocezar (bostezar), lamber (lamer), llares (lares), etc.

Bien es cierto que no todos tienen la misma extensión geográfica, pues mientras algunos se proyectan por toda Extremadura, otros tienen un ámbito más reducido. Muchas de estas palabras llegan a Andalucía e incluso a Canarias, como veremos.

Apurando mucho la cuestión terminológica, cabría decir que aquellas palabras que sólo se registran en la zona noroccidental de Cáceres no son leonesismos sino palabras leonesas conservadas en este ángulo antiguo perteneciente al reino de León. Pero de ello ya hemos hablado y no vamos a insistir más. Caso distinto es el estado que nos reflejan algunos pueblos extremeños de la sierra de Gredos, en concreto los pueblos en las cimas de montañas, como Piornal, etc, y que, pese a pertenecer a la Extremadura castellana tienen rasgos fonéticos claramente leoneses debidos a repoblación leonesa ${ }^{17}$. Por el contrario, cuanto más al sur y más al este de Extremadura, menos son los leonesismos, así en Almendralejo no superan la veintena ${ }^{18}$.

Al contrario de lo que sucedía en Extremadura, contamos con varios estudios sobre los occidentalismos en Andalucía, gracias, en gran parte, a la existencia del ALEA y a los análisis que se han hecho del material en él recogido. Obviamente los leonesismos y occidentalismos se dan sobre todo en el oeste de Andalucía, principalmente en Huelva y más especialmente en la sierra, lo que no quita para que en algunas ocasiones se adentren por otras zonas andaluzas, como veremos. Ya hace años el profesor Alvar ${ }^{19}$ señaló que el topónimo onubense Jabugo (sabucus) indicaba una repoblación de asturianos - Mieres, Canga de Onís - y señalaba la existencia de un topónimo como Zamoranos en el sur de Córdoba $^{20}, \mathrm{y}$, al parecer, gallegos y asturianos participaron intensamente en la repoblación de Cádiz. Ello sin olvidar el influjo de extremeños más o menos "leoneses".

Uno de los primeros estudios basados en el ALEA fue el ya clásico de Julio Fernández Sevilla Formas y estructuras en el léxico agrícola andaluz ${ }^{21}$. No habla exactamente de leonesismos sino de occidentalismos, y considera como tales aquellos "elementos léxicos

17 Vid los estudios de F. Flores del Manzano, más concretamente sus trabajos: "Incidencia del factor histórico en la configuración geolingüística de Extremadura", Actas del I. C. I. H $H^{a}$. L. E., Madrid, 1988, II, pp. 1449-1459; y "Modalidades de habla extremeña en la sierra de Gredos", Actas II C.I. H ${ }^{a}$ L. E,Madrid, 1992, II, pp. 121-134

18 Vid Miguel Becerra: El léxico de la agricultura en Almendralejo, Badajoz, 1992

19 "Derivados de Sabucus en la toponimia peninsular", RFE, XLI, 1957, y "Estructura del léxico andaluz", RFUCh, XVI, 1964

20 "Proyecto de un Atlas Lingüístico de Andalucía", Orbis, II, 1953

21 Madrid, 1975 
comunes con el Occidente español y cuya filiación exacta presenta problemas de difícil solución"22. Son los siguientes: carozo "tronco que queda al desgranar la mazorca"23, sayo "farfolla"24, calabozo "rozón", balaguero "parva trillada y recogida", sobrao/soberao "sitio para guardar el trigo", apañar "coger las aceitunas"25, cabo, "mango de una herramienta", tendales "varales del carro", maza "cubo de la rueda del carro", gajo "racimo", entre otros. No voy a exponer aquí los argumentos de Fernández Sevilla, quizá haré alguna precisión: apañar en todo caso es leonesismo - quizá solo semántico - puesto que difícilmente en portugués $-\mathrm{NN}->\mathrm{N}$; es más, parece que es un castellanismo del portugués ${ }^{26}$. Por el contrario no me parecen portuguesismos sino occidentalismos sacho "escardillo", bago "grano de uva"27. Más problemática es repiar "varear" u "ordeñar los olivos"; problemática porque en Extremadura hay dos acepciones: una, la de "coger las aceitunas con las manos", registrada en Aliseda 28 , otra la de "bailar la peonza o repión", de gran extensión por toda Extremadura. Claro es que la segunda no parece tener la misma etimología, pues resulta claro que es un derivado de pie, como lo es también peonza. Para la primera no creo que tenga nada que ver con el portugués arrepiar "causar miedo, erizarse los cabellos"29, del latín HORRIPILARE

Ana I. Navarro ${ }^{30}$ da como occidentalismos los siguientes términos: horear (ahechar), juera (harnero), lamber (lamer), liuda (levadura), mazaroca (mazorca), rollóm (acemite), sacho/zacho (escardillo) y tojo (aulaga) ${ }^{31}$. Este trabajo tiene como gran inconveniente su pobreza bibliográfica porque la autora se ha limitado a mirar a Portugal y geográficamente se ha ceñido en exclusiva a Andalucía, y, claro, sus conclusiones no son muy exactas. Discrepa en algunas ocasiones de Fernández Sevilla y así considera occidentalismos - como hemos visto - mazaroca y sacho, y como castellana apañar ${ }^{32}$ y cincho, pero sigue considerando portuguesismos bago y zugo o sugo. De la primera ya

\footnotetext{
22 Ob. cit. p. 449

23 Alvar decía que no había testimonio en Extremadura, pero cuando escribe su estudio sobre el maíz - en 1966 - todavía no se había publicado el diccionario de A. Viudas.

24 Que, curiosamente, tiene un área alejada del oeste, pues ocupa el este de Cádiz, casi toda Málaga y pueblos limítrofes de Sevilla y Córdoba. Vid Alvar: Estudios, cit. pp 262-263 y 269. Nada dice el profesor Alvar de que sea occidentalismo.

25 M. Alvar - Estudios, cit. pp. 251 y 256 consideraba que era lusismo privativo de Andalucía; también en Villamiel (Cáceres), muy cerca de Portugal.

26 Antonio Geraldo Da Cunha: Dicionário etimológico, Río de Janeiro, 1989

27 Vid Miguel Becerra: "Geografía linguística de algunos vocablos del léxico agrícola extremeño de posible origen portugués", I Jornadas ibéricas de investigadores en ciencias humanas y sociales, Badajoz, 1986, pp. 109-112

28 A. Viudas: Dic. extremeño

29 Sí con el extremeño arrepío. López de Aberasturi cree que es un extremeñismo de origen portugués ("Extremeñismos léxicos en Andalucía occidental", Actas I. C.I. H ${ }^{a}$ L. E., Madrid, 1988, Ii, pp. 1501-1515.

30 "Occidentalismos en andaluz", EA, 43, 1985, pp. 69-88

31 Que Alvar - Estudios, cit, pp. 254 y 256 - considera lusismo

32 Aunque dice que "el término portugués ha ejercido influencia sobre el español". Ya vimos que era al revés.
} 
hemos hablado ${ }^{33}$, la segunda es un arcaísmo ${ }^{34}$. Lo que sucede es que en el cuerpo del artículo los occidentalismos son - en su opinión - en algunos casos lusismos ${ }^{35}$. Permítaseme copiar el siguiente párrafo de lamber:

"Que lamber aparezca en Huelva y oeste de Sevilla es fácil de explicar por el portugués lamber. Ahora bien, que aparezca en Cádiz y Málaga puede deberse también a una influencia portuguesa, aunque podría ser debido a la presencia de un leonesismo, ya que lamber es un occidentalismo peninsular que también se halla en Canarias. Sin embargo, nos inclinamos a pensar que lamber al este de Cádiz y oeste de Málaga sea la pervivencia de un mozarabismo, pues, como se sabe, este dialecto conservaba los dos elementos del grupo latino"36

En fin, no nos detenemos más en este artículo $^{37}$. Solo añadir que no creo en mozarabismos no probados.

Algunos de los occidentalismos que señalábamos en Extremadura tienen su continuidad en Andalucía e incluso en Canarias; es lo que sucede con afechar/fechadura, coruja, cuadrill, sacho/zacho, etc. No dudo de que la primera sea un portuguesismo, pero coruja "lechuza" se encuentra en Santander, Asturias, Extremadura, Andalucía y las Islas Canarias; demasiada extensión para ser un lusismo, habría que considerarla más bien un occidentalismo, como dijeron Alvar y Llorente.

Ultimamente ha trabajado - y muy bien - en el tema que nos trae Ignacio López de Aberasturi ${ }^{38}$. En el segundo Congreso de Historia de la Lengua Española estudió cuatro términos que procederían directamente de León ya que no hay huellas de su existencia en Extremadura ${ }^{39}$. Serían los que él llama "leonesismos de carácter migratorio" por cuanto supone que fueron llevados directamente por repobladores leoneses. Son cuatro las palabras que estudia: cimbarón "caballón que sirve de señal de límite entre dos fincas" (en unos cuantos puntos de Huelva), gachapo "vasija en donde se guarda la piedra de afilar" - palabra esta cuyo posible leonesismo es problemático, a mi entender -, locajo "cítola del molino, cencerro" en puntos de Huelva y en uno de Sevilla y otro de Cádiz, y morera "hacina, tresnal" en dos puntos de Huelva, voz que aunque también castellana es común con el

\footnotetext{
33 Y se conserva en Babia, Sayago, etc.

34 Caso distinto es sugar/zugar "chupar", que solo se encuentra en las zonas más occidentales de Badajoz

${ }^{35}$ La misma confusión se registra en otro artículo de la misma autora, en donde - por poner algunos ejemplos fechadura se encuentra entre los occidentalismos y los lusismos, y lo mismo ocurre con cañafote, marco y zugo ("Distribución del léxico dialectal del ALEA", Español Actual, 45, 1986, pp. 59-80

36 P. 77

${ }^{37}$ Un último ejemplo: topino tiene una terminación leonesa, no occidental.

38 No he podido consultar su memoria de licenciatura inédita Introducción al estudio de los occidentalismos (leonesismos y portuguesismos) en Andaluz, Granada, 1986, tesina que, curiosamente, no cita J. Mondéjar en su Bibliografía sistemática y cronológica de las hablas andaluzas, Granada, 1989.

${ }^{39}$ Salvo en la zona leonesa de la Región - Hurdes, etc - o en la zona más limítrofe con Huelva, ya en la sierra, como Oliva de la Frontera
} 
leonés. Solo una observación tengo que hacer: existe chocayo "campanilla" en Badajoz ${ }^{40}$, con palatalización occidental.

Para el examen del leonesismo en Canarias me baso en el estudio del profesor Llorente sobre el tomo I del ALEICan ${ }^{41}$. Como era de esperar, no son muchos los leonesismos: trece en total, a los que habría que sumar los occidentalismos otros once. Algunos de estos ya los hemos mencionado en el extremeño y el andaluz occidental, por lo que su paso a las Islas procede del sur y no directamente de la zona leonesa, como es lógico. He aquí la lista de occidentalismos: Bagazo "orujo, corazón de la pera, hollejo", bago "grano de uva, orujo, gajo", baluco "lanza del carro de vacas", canciles "costillas del yugo de la caballería", coruja "lechuza", corza "narria", chaveta "clavija del timón", escoda "zapapico", frangollo "maíz o trigo molidos muy gruesos", sacho "escardillo" y tupirse "obturarse la reguera"42. Los leonesismos serían apitar/pitar "mugir, bramar", baluto "erial", broco "cuernecillo", casullo "cascarilla del trigo, vaina", desbagar "picar en el racimo", feje "gavilla, haz", horrura "heces, ramojo", luir/liuda "crecer el pan/masa fermentada", picocha "zapapico", remoniar "rumiar", seja "piedra de la boca del horno", sirgada "vaca o cabra blanca y negra" y zálamo/sálamo "bozal".

Haré algunas precisiones, con todos los respetos hacia mi admirado D. Antonio. Precisamente por la documentación que él aporta, creo que deben ser considerados lusismos más que occidentalismos - cancill, corza, chaveta y escoda, y, por el contrario, creo que son occidentalismos baluto, broco, feje, seja ${ }^{43}$ y zálamo. Por lo que leonesismos propiamente dichos hay pocos: unos cuatro, y son generalmente leonesismos extendidos por el sur - Extremadura y Huelva - que del sur han pasado a las Canarias.

Algunas consideraciones finales a lo que hemos expuesto:

1) En primer lugar conviene diferenciar entre la pervivencia de términos leoneses en el antiguo territorio leonés y la extensión o propagación de un término leonés fuera de su ámbito histórico. Bien es cierto que en gran parte del antiguo reino de León se habla el castellano desde hace bastantes siglos, pero no es lo mismo que los leoneses hayan conservado restos de su viejo léxico autóctono, que su propagación a otras zonas no leonesas - como el caso de nalga -.

2) A veces se hace difícil decidir si es un leonesismo o un occidentalismo. Lo mismo cabe decir de la diferencia entre lusismo y occidentalismo. En ocasiones es la distribución geográfica la que nos puede hacer inclinar la balanza en un sentido o en otro. De todas formas occidentalismo no se opone a leonesismo o lusismo, sino que es más bien un

40 A. Viudas, ob. cit.

${ }^{41}$ El léxico del tomo I del "Atlas lingüístico y etnográfico de las Islas Canarias, Cáceres, 1987. Más resumido en "Comentario de algunos aspectos del léxico del tomo I del ALEICan", II Simposio Internacional de Lengua Española, Gran Canaria, 1984, pp.283-330

42 Añado el significado "estar lleno": "estoy tupío porque he comido demasiado" en Extremadura

43 Ultimamente ha estudiado la presencia de la palabra en la toponimia andaluza $\mathrm{M}^{\mathrm{a}}$ Dolores Gordón Peral:

"Voces de tipificación occidental en el léxico de las hablas de la Sierra Morena andaluza", Aestuaria, 1, 1993, pp. 126-137 
concepto geográfico, pues en general el origen de su propagación se deberá a leoneses o a portugueses. Pondré algunos ejemplos: si un término se extiende por toda Extremadura, seguramente es un leonesismo; si, por el contrario, solo lo encontramos en pueblos aislados limítrofes con Portugal, lo más probable es que sea un lusismo; si no se registra en Salamanca, Cáceres, Babajoz y aparece en algún punto de Huelva es un lusismo, como sucede - por poner un ejemplo - con arbayo en dos pueblos de Huelva. Lo mismo cabe decir de las Islas Canarias.

3) La inmensa mayoría de los leonesismos y occidentalismos pertenecen al mundo del campo, tan conservador en muchos aspectos. 